\title{
Information, the Dual Economy, and Development
}

\author{
Abhijit V. Banarjee, M.I.T. \\ Andrew F. Newman, Columbia University
}

February 1996; revised May 1997

Discussion Paper Series No. 9697-21

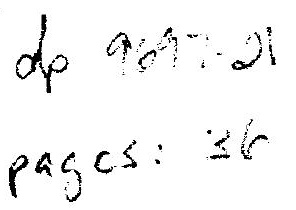




\title{
Information, the Dual Economy, and Development*
}

\author{
Abhijit V. Banerjee ${ }^{\dagger}$ and Andrew F. Newman ${ }^{\ddagger}$
}

February 1996; revised May 1997

\begin{abstract}
We examine the interactions between different institutional arrangements in a general equilibrium model of a modernizing economy. There is a modern sector, where productivity is high but information asymmetries are large, and a traditional sector where productivity is low but information asymmetries are low. Consequently, agency costs in the modern sector make consumption lending difficult, while such loans are readily obtainable in the traditional sector. The resulting trade-off between credit availability and productivity implies that not everyone will move to the modern sector. In fact, the laissez-faire level of modernization may fail to maximize net social surplus.

This situation may also hold in the long run: in a dynamic version of the model, a "trickle-down" effect links the process of modernization with reduction in modern sector agency costs. This effect may be too weak and the economy may get stuck in a trap and never fully modernize. The two-sector structure also yields a natural theoretical testing ground for the Kuznets inverted- $U$ hypothesis: we show that even within the "sectoral shifting" class of models, this phenomenon is not robust to small changes in model specification.
\end{abstract}

*An earleir draft of this paper circulated under the title "Migration, Integration, and Development" (February, 1994). We are grateful for comments from Tim Besley, Shubham Chaudhuri, Raquel Fernandez, Ron Findlay, Thomas Piketty, Nouriel Roubini, T.N. Srinivasan, Peter Timmer, Chris Udry, Jeff Williamson, three anonymous referees and the editors of this journal, and seminar participants at M.I.T., N.Y.U., Princeton, Columbia, Madrid (Carlos III), L.S.E., Cornell, Boston University, Toronto, Harvard, and Yale. The second author thanks the Institute for Policy Reform for financial support.

${ }^{\dagger}$ Department of Economics, Massachusetts Institute of Technology, Cambridge, MA 02139

$\ddagger$ Department of Economics, Columbia University, New York, NY 10027 


\section{Introduction}

The process by which an underdeveloped economy transforms itself into a developed one involves more than just a rise in living standards. It usually brings about substantial changes in the way people conduct their entire lives - their social relations, their levels of urbanization and commercialization, even their political roles. In this paper we look at the relation between this process of institutional change - often called modernization - and the process of economic change that seems to go with it.

We take the view that these processes are not independent; nor is modernization merely a product of economic growth. Rather they are autonomous processes which interact with each other and can, under different circumstances, either promote or retard each other. While this position is not entirely uncontroversial, there is now a sufficiently impressive body of evidence in support of this point of view to warrant its exploration in a formal model. ${ }^{1}$

We study an economy consisting of two sectors which are distinguished in two ways: technological and institutional. One sector has a more modern technology, and is therefore more productive, but people live and work in different places and are essentially anonymous - the information they have about each other is poor. By contrast, the other sector is more traditional: the technology is less productive, but because people live and work together, they know a lot about what is going on in the lives of their neighbors.

This difference in the degree of information asymmetry is important because people in this economy sometimes need consumption loans. Loan transactions are subject to default by the borrower and as a result, lenders are reluctant to lend to those who cannot provide a significant amount of collateral. The superior information in the traditional sector allows lenders to monitor borrowers better; as a result, each individual borrower gets as good or better access to credit than he would be able to get in the modern sector. This sets up a trade-off between the superior access to credit in the traditional sector and the higher productivity in the modern sector. It follows that some of the population will fail to migrate to the more productive sector, even long after the opportunity to move becomes available.

The first result in the paper identifies those who have the most incentive to leave the traditional sector and work in the modern sector. They are the wealthiest, the most productive and possibly, the poorest and least productive. The wealthy leave because they can finance the consumption on their own and do

\footnotetext{
${ }^{1}$ Among economic historians this line of argument has been developed by North and Thomas [19], Mokyr [18] and Rosenberg and Birdzell [21], among others. See also Baumol [6]. Among political historians see, for example, the work of Putnam[20].
} 
not need loans, the most productive leave because they have much to gain and the poorest and least productive leave because they have nothing to lose - they cannot get a loan in either location.

A second result, which is implicit in the first, is that more people will move to the modern sector when the interest rate is either very low (at low interest rates the temptation to default is weak and therefore the advantage from being able to monitor better is more limited) or very high (no one can afford to take out a consumption loan).

Our third result says that the equilibrium rate of movement out of the traditional sector may be lower than the socially optimal rate (where social welfare is measured by net social surplus). ${ }^{2}$ This is because as long as there are a lot of people in the traditional sector, the economy-wide market for consumption loans works well on average (because the quality of information is high for most of the people). This allows the lenders to charge a higher rate of interest on these loans than they would be able to charge if the market worked less well. But given that the market rate of interest is high, ${ }^{3}$ a lot of people may be reluctant to leave the traditional sector. Therefore this kind of a situation can be an equilibrium. Now suppose that everyone in the traditional sector was forced to move to the modern sector. Because of the lower quality of information, there will be fewer people who are good credit risks from the point of view of the lenders. Competition for these people will drive the interest down to the point where more and more people will be able to get consumption loans even in the modern sector. Therefore the number of people who, in equilibrium, get consumption loans may not shrink (or shrink very much) while the number of people who are working in the more productive sector goes up by a lot. Therefore the social surplus must be larger in the new situation.

This 'inefficiency' result provides a formal statement of what it can mean for modernization to be too slow. It reflects the general principle that in information constrained economies, the market equilibrium may not be surplus maximizing. ${ }^{4}$ Now, in order to keep the model simple we have left out the important but wellunderstood effects of congestion in the modern sector; these effects typically result in the equilibrium rate of modernization being too high rather than too low. Thus, the inefficiency result should be viewed less as a guide to policy and more as a illustration of the general point that an institution that appears to work well (in this instance, the system of lending in the traditional sector) may actually end up

\footnotetext{
${ }^{2}$ Williamson [28] surveys the evidence on whether the rate of migration to the modern sector is optimal and argues that there is at the very least no clear evidence of over-migration.

${ }^{3}$ But not too high (see the discussion in the previous paragraph).

${ }^{4}$ On the other hand, we have not established that the equilibrium is inefficient in the Pareto sense - indeed, our conjecture is that it is constrained Pareto efficient.
} 
hurting the people it appears to be helping (the people who stay in the traditional sector in order to get the consumption loans) once one takes into account general equilibrium effects.

We go on to try to characterize the set of economies where this kind of inefficiently slow modernization is likely to emerge. We show is that it is less likely both in very poor and very inegalitarian economies and in very rich economies than in the intermediate range of economies.

Turning next to dynamics, we observe that our model builds in a two-way interaction between the process of growth and the process of institutional change. On one side, the rate of growth in this economy depends on how many people take advantage of the new technology and is therefore constrained by the institutional difference between the traditional sector and the modern sector. Conversely, the long run survival of the traditional institutions depends on the rate of growth. This is because the price of loans (i.e. the rate of interest) depends on the supply of capital: as the economy grows, capital becomes abundant and the price of loans in both sectors falls. Since falling interest rates reduce agency costs in the modern sector, the comparative advantage of the traditional sector in the provision of loans is diminished, and people are further encouraged to emigrate to the modern sector.

The dynamics of our model are in principle quite complex, and we provide only a partial characterization. Nonetheless, we are able to provide conditions under which the economy fully modernizes in the sense that the traditional sector vanishes. We can also show that full modernization is not inevitable - an economy can partially modernize and then stop.

We also look at the income distribution implications of the process of modernization. Forty years ago, Kuznets [16] concluded on the basis of a study of the process of modernization in a number of then-developed countries that the initial impact of modernization was to increase inequality but that over time, inequality would decrease as the economy approached full modernization. This prediction for the pattern of evolution of inequality is what is known as the Kuznets inverted U-hypothesis and has been the subject of many empirical studies and much controversy in the development literature (e.g. [1], [11], [12], [28]). The favored explanation (there have been others, e.g. [2], [7]) for why such a pattern should emerge seems to be based on the shifting of the population from a low wage sector to a high wage one (see e.g. [3]); thus a model such as ours is the natural place to give the inverted- $U$ hypothesis its best shot and ask whether it does indeed have robust theoretical foundations.

We show that these underpinnings are anything but robust. In one case the predictions of our model correspond exactly to the Kuznets hypothesis. But this result is very sensitive to assumptions about self-selection in the decision to move 
to the modern sector. By altering these assumptions in seemingly inconsequential ways, we are able to generate a range of patterns for the evolution of the income distribution, including one in which inequality decreases, then increases during the course of modernization, in effect turning Kuznets on his head. This finding might explain why some countries seem to follow the Kuznets pattern, while others do not.

Our results are clearly driven by the specific assumptions we make. The basic premise that the traditional sector as a relatively low level of information asymmetry (so for instance provides surprisingly good insurance) is supported by studies of consumption smoothing ([25], [26]). A number of recent papers have also argued that the remarkable success of certain traditional sector institutions (such as Grameen banks in Bangladesh and the 19th century German credit cooperatives) derive from the high quality of information that people in the traditional sector have about each other ([24], [27], [4]). There is also a lot of evidence that idiosyncratic risks are very important, at least in traditional agriculture. ${ }^{5}$ The relative anonymity of life in the modern sector is all too familiar to require proof. Finally the one survey of people's motives for remaining in traditional sector that we are aware of ([9]), finds that access to informal security mechanisms such as consumption loans is the main reason why people do not move.

Our analysis is devoted to understanding the effects of interactions of different institutional structures in a developing country. Naturally, our assumptions are strong: for instance, the idea that once one starts working in the modern sector one is completely cut off from the traditional sector, is an exaggeration of how things really work. A number of studies have stressed the fact that one remains closely connected to the family or even the extended family, long after one has physically moved to the modern sector. At the same time, however, there is also evidence of conflict and moral hazard between those who have moved and those who remain. ${ }^{6}$ A variant of our assumption that would therefore be closer to the truth is that one retains imperfect access to the security mechanisms of the traditional sector for some time after one has moved. We believe that our

\footnotetext{
${ }^{5}$ See Townsend [25] to get some sense of the size of the risks faced by villagers in semi-arid parts of India.

${ }^{6}$ Stark [23] using data from Botswana has argued that the fact that remittances from urban immigrants to their families based in rural areas rises with the migrant's income is evidence for a coopertaive outcome within the family. However, the same result would also obtain if there was moral hazard within the family which was only partly mitigated by the repeated-game considerations that Stark has empahasized. Williamson [28], surveying studies of remittances from migrants to their families, suggests that there is some evidence which supports high default rates among migrants and concludes that the amount of control the family has over those who migrated is an open empirical question.
} 
qualitative results are robust to this kind of change in assumptions. ${ }^{\top}$

Our work follows on a tradition in development economics of studying modernization which goes back to the work Arthur Lewis [17]. Our two-sector economy is a dual economy in the sense of Lewis and the question we ask about the determinants of the rate of modernization and whether the rate of modernization is optimal, are very much the questions Lewis asked in his classic paper more than 40 years ago. Our work departs from the work of Lewis and others in this tradition ${ }^{8}$, in not assuming a difference in the nature of economic rationality between the two sectors. ${ }^{9}$ Our agents are equally rational wherever they are - the differences between the two sectors are technological and informational.

Finally, a remark about interpretation - we model the actual act of moving to the modern sector as an act of migration from the rural sector to the urban sector. The words, rural and traditional, urban and modern and migration and modernization will be used interchangeably in the paper. This is done partly to give a specific content to the idea of modernization and partly because migration is one very important channel through which modernization takes place. Nevertheless we want to emphasize that this is only one interpretation of the model; nothing in the model requires that the move from the traditional sector to the modern sector should involve physical displacement. Indeed, as has often been noted, in some developing countries, migrants to cities often reproduce the social networks formerly located in their villages. But membership in a network is costly, and full engagement in the modern sector typically requires participation in different networks or in a high degree of mobility (the latter is often cited as a source of the modern sector's higher productivity) which makes the maintenance of close social ties impossible. The point is that the patterns of income and inequality generated by our model may be valid even if they do not manifest themselves in the patterns of migration: everyone might move from village to city, but the economy will still be slow to modernize.

\footnotetext{
${ }^{7}$ As they are to the observation that migration can provide a degree of insurance against village-level aggregate risk by diversifying the family's income. This benefit of migration works in essentially the same way as the productivity boost, and in any case does not gainsay the fact that migration has costs in the form of lost idiosyncratic insurance.

${ }^{8}$ See for example Fei and Ranis [10], Harris and Todaro [14] and Sen[22].

${ }^{9}$ Lewis, for example, assumed that members of a family farm are always paid their average product as long as they remain on the farm but are not paid once they leave. This is obviously not the optimal contract for the family farm since it discourages people from leaving even though they would be more productive elsewhere. There is now substantial evidence that the family farm does act as an economically rational unit when it takes migration decisions, which puts into question this assumption. [8]
} 


\section{The Model}

In this section and the next, we consider a one period model. There are just two locations - a village representing the traditional sector and a city representing the modern one. The economy has a single perfectly storable consumption good and a continuum of agents. A typical individual begins life with an initial wealth $a$. He makes a location choice which has no direct cost - labor is freely mobile. In his youth, before entering his productive phase, an individual has a chance to consume an indivisible good which yields utility $s$ and costs $m$ units of the good (to fix ideas we will think of this good as a form of schooling that does not affect future wages. It could equally be medicine or a wedding - it just should not be an investment that affects future incomes $)^{10}$. If his wealth is insufficient to finance schooling, he may attempt to borrow the difference. In adulthood, the individual earns his income from labor, which he supplies inelastically, and repays any loan obligations. The von Neumann-Morgenstern preferences have the form $y+u$, (so the agent is risk-neutral in net income $y$ ), where $u$ denotes the utility from schooling, which is either $s$ if $m$ is consumed, or 0 if it is not.

The first crucial assumption is that productivity is higher in the city than in the village. We model this by assuming that an individual who can earn $w$ in his village could earn $\lambda w$ in the city, where $\lambda>1$. In a first-best world, where information was not at issue, everyone could borrow and lend at the market gross interest rate $r$ (the only reason to borrow would be to finance school). Thus every individual would move to the city, enjoy a utility of $\lambda w+s+(a-m) r$, and the economy would operate efficiently.

But this is not a first-best world, and this fact affects the workings of the market for consumption loans. We assume that capital is freely mobile between the two locations and that there is free entry of lenders in both locations. What is not mobile is information and enforcement powers. The consumption loan market is distinguished by the possibility that a borrower might renege on a debt. Suppose an agent has wealth $a$; he borrows $m-a$. As part of the lending agreement, he promises to keep the lender abreast of his whereabouts. Should the borrower attempt to flee the agreed upon location before he has earned his income, the lender can detect him with probability $\rho$. If detected, the borrower is punished maximally by having his consumption held to zero; ${ }^{11}$ if he escapes (presumably to the city), he will be able to consume his entire gross income. After earning his

\footnotetext{
${ }^{10}$ We can actually allow it to be an investment but the result is a much more messy model.

${ }^{11}$ We assume that the lender commits to this punishment policy, which strikes us as plausible in this context. We could instead let the lender and borrower renegotiate at this stage; this would have the effect of reducing the efficiency of the loan market in each sector, but not the relative efficiency between the sectors. Thus it would complicate the notation but not change the conclusions very much.
} 
income, it comes time to repay the loan, and he may again attempt to avoid his obligations by fleeing from the purview of the lender. At this stage, the borrower succeeds in escaping attempts at recovering the loan with probability $\pi$; with probability $1-\pi$ he is caught before he has a chance to dispose of his income and again a maximal punishment is imposed which holds his consumption to zero.

This situation leads lenders to require that loan contracts satisfy incentive compatibility constraints ex-post, that is after income is earned, and ex-ante, that is when borrowers could renege on the location agreement. Suppose that if the borrower earns $y$ ( $=w$ or $\lambda w$ depending on where he locates) he is to repay $P(y)$ and that the income to be earned is known at the time of contracting; then ex-post incentive compatibility requires $y-P(y) \geq \pi y$ for each $y$. Competition among lenders will ensure that $P(y)=(m-a) r$; hence ex-post incentive compatibility entails $y-(m-a) r \geq \pi y$ or $a \geq a_{P} \equiv m-\frac{(1-\pi) y}{r}$.

Since the contract will satisfy this condition, the borrower knows that if he tries to flee before earning his income, he can get at most the expected payoff of $\rho \lambda w$, whereas if he remains where he agreed, he gets $w-(m-a) r$ (in the village) or $\lambda w-(m-a) r$ (in the city). Thus there is also an ex-ante incentive constraint that $a \geq a_{A}^{V} \equiv m-\frac{(1-\rho \lambda) w}{r}$ (if he agreed to stay in the village) or $a \geq a_{A}^{C} \equiv m-\frac{(1-\rho) \lambda w}{r}$ (in the city). All loans made in equilibrium will satisfy these constraints, and the borrower will never renege. ${ }^{12}$

Since an agent who agrees to work in location $l=V, C$ needs exactly $m$ to pay for youthful consumption, his initial wealth must satisfy $a \geq a_{l}=\max \left\{a_{P}, a_{A}^{l}\right\}$ if he is to borrow at all; if his wealth is below this threshold value, he will be unable to pay for the consumption. Observe that this threshold value of wealth $a_{l}$ is increasing in the interest rate, decreasing in income, and increasing in the escape probabilities $\pi$ and $\rho$; this simple, if perhaps extreme, model of an imperfect loan market accords in its conclusions with those of other agency models.

We now use this model to distinguish the informational advantage of the village over the city. Specifically, we make the extreme assumption that escape is impossible if one is born and remains in the village; any attempt to escape either ex-ante or ex-post would immediately be detected by the local network or village moneylender. Hence, $\rho=\pi=0$ there, and the threshold wealth is $m-w / r \equiv a_{V}(w, r)$ : as long as the individual's wage in the village exceeds $m r$, she can borrow and go to school. If instead she locates in the city at any time in her life (either by choice or by birth), $\pi$ is large in the sense that $\lambda(1-\pi)<1$; thus, $a_{C}(w, r) \equiv m-(1-\pi) \lambda w / r>a_{V}(w, r)$ for all $w$ and $r$. We also assume

\footnotetext{
${ }^{12}$ If we assume that the income level is not realized until ex-post, then the ex-post constraint is replaced by a set of constraints of the same form; competition implies $E P(y)=(m-a) r$ and the ex-ante constraint becomes $a \geq a_{P} \equiv m-\frac{(1-\pi) \bar{y}}{r}$, where $\bar{y}=E y$. The ex-ante constraints assume the same form, with $w$ replaced by $\bar{w}$.
} 
that $\rho=\pi$ for loans originating in the city, but $\rho=0$ for loans originating in the village. ${ }^{13}$

This market imperfection is the source of the possibility of undermigration: an individual whose wealth lies between the threshold values $a_{C}(w, r)$ and $a_{V}(w, r)$ would indeed gain a higher wage by migrating, but would be giving up the possibility of consuming during youth. (Note that it is never socially or individually optimal for someone born in the city to move to the country, because he faces the same value of $\pi$ but earns a lower income.) It remains to be shown that this possibility is compatible with competitive equilibrium.

\section{Static Equilibrium}

Normalize the population of adults in the world in any period to be of Lebesgue measure 1. Denote by $R(a)$ the measure of people born in the village with wealth less than $a$ at the beginning of the period. Denote by $U(a)$ the corresponding measure in the city.

Let us now consider the choice problem faced by the those born in the rural sector. Given an interest rate $r$, an agent with $a \geq a_{C}(w, r)$ has a payoff of $w-m r+a r$ if he stays in the village and $\lambda w-m r+a r$ if he moves to the city, so he clearly will migrate. If his wealth is less than $a_{V}(w, r)$, he will also migrate because he doesn't get a loan in either location and so takes the higher urban wage. An agent with wealth between $a_{C}(w, r)$ and $a_{V}(w, r)$ however, will migrate only if $w-m r+a r \leq \lambda w-s+a r$, i.e. if $r \geq \frac{s}{m}-\frac{(\lambda-1) w}{m} \equiv \hat{r}(w)$. What this tells us is that migration will tend to be carried out by the relatively wealthy and by those for whom the market interest rate exceeds $\hat{r}(w)$; since this is a decreasing function of $w$, it is those with the highest incomes (e.g. the most skilled) who will migrate. Finally, very poor low-skilled people may also migrate - this requires that their skill levels are low enough to make $a_{V}(w, r)$ positive; if not, even agents with zero wealth will be able to borrow for school and will remain in the village.

To summarize, we have

Proposition 3.1. An agent born in the village with wealth $a$ and who earns $w$ there migrates to the city when the interest rate is $r$ only if (a) $a \geq a_{C}(w, r)$ or (b) $r \geq \hat{r}(w)$ or (c) $a<a_{V}(w, r)$.

\footnotetext{
${ }^{13}$ Thus if one borrows from a village moneylender but agrees to locate in the city, one faces exactly the same constraint that one would face if one simply moved to the city and borrowed there.
} 
As we have already noted, those who grew up in the urban sector never have reason to migrate to the village. See Figure $1(\hat{w}(r)$ is the inverse of $\hat{r}(w)$, i.e. the income level at which an agent is indifferent between staying in the village with a loan and moving to the city without it).

Given this proposition, the supply and demand for loans can be characterized very simply. For the remainder of this section we assume that everyone earns the same income, so that agents only differ in initial wealth; thus we might as well write $a_{C}(r)$ and $a_{V}(r)$ for $a_{C}(w, r)$ and $a_{V}(w, r)$ evaluated at this common value of $w$, and $\hat{r}$ for $\hat{r}(w)$. All of those with wealth above $a_{C}(r)$ demand loans, as do those with wealth less than $a_{C}(r)$ who remain in the village. If the interest rate is greater than $\hat{r}$, everyone migrates, so the demand for loans is $m\left[1-R\left(a_{C}(r)\right)-U\left(a_{C}(r)\right)\right]$, which is decreasing (at $r=\frac{s}{m}$, the demand is the interval $\left[0, m\left[1-R\left(a_{C}\left(\frac{s}{m}\right)\right)-\right.\right.$ $\left.\left.\left.U\left(a_{C}\left(\frac{s}{m}\right)\right)\right]\right]\right)$. At $\hat{r}$, those villagers with wealth below $a_{C}(\hat{r})$ but above $a_{V}(\hat{r})$ are indifferent between the two locations, so the demand becomes an interval $\left[m\left[1-R\left(a_{C}(\hat{r})\right)-U\left(a_{C}(\hat{r})\right)\right], m\left[1-R\left(a_{V}(\hat{r})\right)-U\left(a_{C}(\hat{r})\right)\right]\right] ;$ as $r$ declines further demand becomes $m\left[1-R\left(a_{V}(r)\right)-U\left(a_{C}(r)\right)\right]$, eventually reaching its maximum value of $m$. Supply is simply the aggregate wealth $\bar{a}$. Thus equilibrium, if it exists, is generically unique. ${ }^{14}$ It is straightforward to check that the maximum equilibrium gross interest rate is $s / m$, while because the good is storable, the minimum is 1 .

Figure 2 illustrates the situation. Also shown are the demand functions which would result in the first-best case without information problems (this is also the demand function for a pure village economy in which there was no urban sector to migrate to), and the demand from a pure urban economy (say one in which everyone was forced to move to the city).

We can now check whether the equilibrium level of migration is efficient in the sense of making full use of the existing supply of resources. In particular we shall ask whether social surplus could be increased relative to its equilibrium level by forcing agents to choose locations in some way other than the one which occurs in equilibrium. ${ }^{15}$ Thus we shall not be concerned here with the possibility of increases in social surplus which might be obtained from interventions in the loan market or from tax and transfer schemes more generally. We should also note at this point that, as is often the case in economies in which incentives and

\footnotetext{
${ }^{14}$ Existence is guaranteed if $R(\cdot)$ and $U(\cdot)$ are continuous. With such distribution functions, the only case of nonuniqueness occurs in the nongeneric case in which $\bar{a}=m$, in which case we focus on the equilibrium where $r=1$, which is the one that maximizes the level of migration and social surplus.

${ }^{15}$ Surplus here is defined here as total output plus the net value of all youthful consumption - thus the maximum surplus an economy with mean wage $\bar{w}$ and mean wealth $\bar{a}$ can generate is $\lambda \bar{w}+\bar{a}(s / m-1)$.
} 
wealth effects play a role, the potential surplus increases under discussion cannot typically be transformed into Pareto improvements.

On the face of it, we should expect that any situation where some agents remain in the rural sector is a candidate for inefficiency. To see this, note that labor in the rural sector is being used inefficiently. If a small number of people were moved to the urban sector, more income would be generated. This reduces the demand for loans however, but if the interest rate is able to fall, the wealth that is no longer being used in the rural sector can flow to the city, clearing the market at a lower interest rate, as shown in Figure 2. ${ }^{16}$

The next step is to determine whether and under what conditions an inefficient equilibrium actually exists. Figure 3 illustrates the level of migration as a function of the equilibrium interest rate. Clearly a necessary condition for inefficiency is that the equilibrium $r$ be no higher than $\hat{r}$. Since 1 is the lowest equilibrium value of $r$,inefficient undermigration requires that

$$
(s-m) \geq(\lambda-1) w .
$$

The necessity of this condition is clear: if the productivity differential between village and city is large ( $\lambda$ is large), then the attraction of the city is enough to swamp the possible lack of school, and everyone migrates. By the same token, if the value of the loans is small ( $s$ is close to $m$ ), undermigration is unlikely, since poor people have little to lose by leaving their village.

As is evident from Figure 2, the existence of inefficient undermigration depends in part on the mean level of wealth. But it also it depends on the higher moments of the wealth distribution. A complete characterization for continuous distributions of wealth is offered in the following

Proposition 3.2. Suppose condition (3.1) holds and $R(\cdot)$ and $U(\cdot)$ are continuous. Then the level of migration is inefficient if and only if (a) $1-R\left(a_{V}(1)\right)-$ $U\left(a_{C}(1)\right)>\frac{\bar{a}}{m}$ and $(b) \frac{\bar{a}}{m}>\left[1-R\left(a_{C}(\hat{r})\right)-U\left(a_{C}(\hat{r})\right)\right]$.

Proof. First, suppose that conditions (a) and (b) hold. Condition (a) ensures that the equilibrium interest rate $r^{*}$ is greater than one, while Condition (b) implies that at least some agents remain in the rural sector. There are now two cases. If $\frac{\vec{a}}{m} \leq 1-R\left(a_{C}(1)\right)-U\left(a_{C}(1)\right)$, then moving all people to the urban sector raises output (because they are more productive) without changing the surplus from youthful consumption, because the loan market will now clear at a

\footnotetext{
${ }^{16}$ This does not say that the optimal allocation has everyone moving to the urban sector, since if the interest rate cannot fall enough, some of the wealth would be consumed rather than being used for school. This will be clarified below.
} 
new interest rate lower than $r^{*}$. Thus, surplus increases, and the original level of migration was inefficient. If instead $\frac{\bar{a}}{m}>1-R\left(a_{C}(1)\right)-U\left(a_{C}(1)\right)$, one can increase surplus by requiring $\frac{\bar{a}}{m}-\left[1-R\left(a_{C}(1)\right)-U\left(a_{C}(1)\right)\right]$ agents with wealth less than $a_{C}(1)$ (this quantity is less than $R\left(a_{C}(1)\right)-R\left(a_{V}(1)\right)$ by Condition (a)) to stay in the village and sending everyone else to the city; this clears the loan market at $r=1$ and increases output by increasing the number of people in the city.

Conversely, suppose that (a) fails to hold, i.e. that $r^{*}=1$. Then moving anyone from the village to the city increases output, but they will now be unable to get a loan since the interest rate cannot fall (their wealth must be less than $a_{C}(1)$ or they already would have moved); by (3.1) this entails a net loss of surplus. If (b) fails, then as we have seen, everyone migrates, so equilibrium is efficient.

This proposition is the central result of this section. It helps to shed light on exactly what the rural institution is doing. Clearly, since in the initial equilibrium there are people who choose to remain in the traditional sector, they are paying less in interest in the traditional sector than they would in the modern sector (more precisely, they are getting loans there that they would not get in the modern sector). In other words, the rural credit institution does facilitate borrowing. On the other hand if they were moved to the modern sector the wealth they were using would not lay fallow: somebody would end up using it in the more productive modern sector. The interest rate would fall to make this possible; in other words the rural credit institution creates inefficiency by allowing the interest rate to be set too high relative to its second-best level.

One special case deserves to be underscored. If the economy is wealthy in the sense that $\bar{a} \geq m$, migration is always efficient (condition (a) is violated in this case). Since, as we have said, poor economies will tend to have efficient migration as well (although this is not necessary), it is the middling economies, where the villagers have something to lose but wealth is not yet so plentiful as to render the urban agency problems nugatory, that are the best candidates for inefficient undermigration.

Observe that the falling interest rate which results from a policy of forced migration will hurt net lenders (which may include very poor agents as well as the very wealthy); the beneficiaries would tend to be those at the middling wealth levels. But as we suggested before, it appears unlikely that there are taxes and transfers can turn the surplus increase into a Pareto improvement.

We summarize this section by noting that if the urban sector is suddenly opened to a very poor economy, there should be full migration (the interest rate is likely to be higher than $\hat{r}$ ). Only if the rural economy has a sufficiently high aggregate wealth is undermigration likely to be a problem. The degree of un- 
dermigration will depend not only on the aggregate level of wealth but also on its distribution. For instance, if the distribution is fairly inegalitarian while the mean is reasonably high, $R\left(a_{C}(\hat{r})\right)$ is likely to be large, so that it is quite easy for undermigration to occur. The general point to note is that distribution of wealth in the two sectors is the state variable which tells us, among other things, how many people migrate. Thus if we can generate an account of the dynamics of the wealth distribution, we will also have generated the rate of migration and modernization endogenously.

\section{Some Rudimentary Dynamics}

There are two things we hope to accomplish by studying a dynamic version of this model. First, we want to check whether the undermigration that we have identified as a possibility in the short run is actually a possibility when the distribution of wealth (which affects both demand and the supply side of the loan market) is endogenous, and more generally whether there is a possibility that this could be a long run phenomenon: is there a undermigration trap? Second, having developed a two sector model of a developing economy in which the rate of migration is endogenous (as are the "adjustment costs"), we can re-examine some traditional questions about the relationship between modernization and income distribution in a setting which is comparable to the ones in which they were originally asked: specifically, does the "sectoral shifting" account of modernization provide robust foundation for the famous Kuznets inverted U?

We consider these issues by starting with a purely rural economy and examining the level of migration and the distribution of labor earnings over time after the urban sector is opened. A full analysis of the global dynamics of the model seems to be intractable, ${ }^{17}$ and in any case is beyond the scope of this paper, so we limit ourselves to a few special cases which nevertheless illustrate how the migration dynamics can lead to a variety of patterns of the evolution of inequality.

In order to study the dynamics in the simplest possible way, we need to elaborate a bit on the timing and preferences used in the previous sections. We restore the assumption that there is a multitude of skill levels $w$; we shall make alternative assumptions about whether these are known at the time migration decisions

\footnotetext{
${ }^{17}$ Ours is one of a class of dynamic income distribution models characterized by a nonlinear recursive map on the space of wealth distributions. Because there appear to be no general results on such dynamics, most analysts have proceeded by reducing the dimension of the problem, either by studying certain parametric special cases (e.g. [5]) or by restricting attention to families of distributions (e.g. lognormal) which are closed under the individual (loglinear) transition rules (e.g. [13]). We shall follow a combination of these two tacks: somewhat paradoxically, by complicating the model slightly, we are able to simplify the analysis considerably, reducing the problem to a single dimension.
} 
are made. The economy lasts an infinite number of periods and the population is stationary. In every period an individual receives his initial wealth in the form of a bequest from his parent. Adult consumption and earnings occur twice, at dates 1 and 2 within the period. The utility is of the form $u+c_{1}+c_{2}^{1-\beta} b^{\beta}$, where $u$ is the indicator of youthful consumption, $c_{i}$ is adult consumption at date $i$, and $b$ is the bequest. Location choice, borrowing and youthful consumption occur before date 1; uncertainty (if any) about skill level is resolved at date 1, and the wage earned at date 2 is the same as that earned at date 1 . The agent's date 1 consumption occurs after repaying any loans (below we shall make assumptions to guarantee that repayments can be made out of a single date's earnings). If the agent earns $y$ at each date, his indirect utility is $u+(1+\delta) y+\frac{u}{s}(a-m) r$, where $\delta \equiv \beta^{\beta}(1-\beta)^{1-\beta}<1$. Finally, assume that agents who are caught after reneging on loans are subject only to having their date-1 income confiscated; date-2 income is inappropriable. ${ }^{18}$

Notice that with these preferences, the marginal utility of a dollar at date 1 exceeds that at date 2 . This introduces the possible need for a second consumptionloan market, distinct from the school loan market: agents have an incentive to borrow against date 2 earnings in order to consume at the first date. Equilibrium in this consumption-loan market would entail that the gross interest rate there be equal to $1 / \delta$. One equilibrium allocation - the one we shall focus on exclusively - has each agent consuming date-1 earnings net of loan repayments at date 1 , and splitting date- 2 earnings between date- 2 consumption and the bequest; in particular, no one is actually borrowing or lending between dates. This is the unique symmetric equilibrium and the only one that would be compatible with even a slight imperfection in the consumption loan market.

Under these assumptions, the bequest, which is identical to the offspring's initial wealth, is equal to $\beta y$, provided that $y$ is large enough to cover any loan repayments. This specification of preferences, earnings levels and the consumption loan market yields exactly the same one-period behavior that we saw in the previous sections. Moreover, it greatly simplifies the analysis of the dynamics; in particular, the information contained in the distribution of wealth in each location is summarized by the single number $R$ denoting the fraction of the population in the rural sector. Since our purpose is to illustrate the variety of possible dynamic behavior generated by migration (as distinct from wealth accumulation, which has been studied by many authors), rather than to make strong predictions, we feel justified in imposing this structure.

Finally, for what follows we need to distinguish between two alternative as-

\footnotetext{
${ }^{18}$ If one assumes instead that lifetime income can be held to zero, the expressions for $a_{C}(r)$ and $a_{V}(r)$ become $m-(1+\delta)(1-\pi) \lambda w / r$ and $m-(1+\delta) w / r$; this is nearly inconsequential for the analysis but requires some cumbersome modification of notation.
} 
sumptions about when an agent's skill becomes known (to himself and the public alike). In one case, this information is not learned until date 1 ; in the second it is known at birth. It turns out that this small change in timing assumptions can have a dramatic effect on the pattern of evolution of inequality.

\subsection{Full Modernization and the Kuznets curve}

Suppose first that agents learn their skill level after choosing a location (to be precise, at date 1), so that their decisions correspond to the one-wage case considered in Section 3. Let the distribution of skills (corresponding to village labor earnings) be $F(w)$, which is supported on a nondegenerate interval $\underline{\underline{w}}, \overline{\bar{w}}]$ with density $f(w)$, mean $\bar{w}$, and variance $\sigma^{2}$. The distribution of earnings among those in the city is then $F\left(\frac{w}{\lambda}\right)$.

In order to guarantee that agents repay loans out of date-1 earnings alone, we need to assume that $\underline{\underline{w}} \geq s$ ( $s$ is the largest possible value of $m r$, since $r \leq$ $s / m$.) Notice that this implies that the fraction of villagers born with wealth less than $a_{V}(r)$ is always zero ( the largest value of $a_{V}(\cdot)$ is $m-\frac{\bar{w}}{s / m} \leq m-\frac{\overline{\bar{w}}}{s / m} \leq$ $\left.m-\frac{s}{s / m}=0\right)$ : villagers can always insure. We are only interested in the case in which average wealth $\bar{a}$ is less than $m$, since in the other case modernization is instantaneous. Thus we assume that $\beta$ is small enough that $\beta \bar{w}<m$.

For ease of computation, we use the coefficient of variation as an inequality measure. Suppose that in period $t$ the population of the rural sector at the beginning of the period (i.e. before the location decisions) is $R_{t}$; then the urban population is $1-R_{t}$. This will serve as the state variable; we don't need to consider any higher dimensional objects such as the wealth distribution: since an agent whose income realization is $w$ and who remains in the village in period $t-1$ bequeaths $\beta w$ to his child, the fraction of the rural population at the beginning of period $t$ with wealth less than $x$ is given by $F\left(\frac{x}{\beta}\right)$; thus the rural wealth distribution is just $R_{t} F\left(\frac{x}{\beta}\right)$, while the urban distribution is $\left(1-R_{t}\right) F\left(\frac{x}{\lambda \beta}\right)$.

The distribution of wages in the economy in period $t$ is then given by $R_{t+1} F(w)+$ $\left(1-R_{t+1}\right) F\left(\frac{w}{\lambda}\right)$ (by our notational convention, $R_{t+1}$ is the rural population after people choose their locations and so represents the relevant population for computing the distribution of incomes). One can readily check that inequality is equal to $\frac{\sigma}{\bar{w}}$ when $R=0$ or 1 , is increasing at 0 , decreasing at 1 , and has a (unique) maximum at $R=\frac{\lambda}{\lambda+1} \cdot{ }^{19}$ Since mean income $R \bar{w}+(1-R) \lambda \bar{w}$ is decreasing in $R$, if we

\footnotetext{
${ }^{19}$ These properties can be established using the expression for the coefficient of variation, which is

$$
\sqrt{\frac{\left[R+(1-R) \lambda^{2}\right]\left(\sigma^{2}+\bar{w}^{2}\right)}{[R+(1-R) \lambda]^{2} \bar{w}^{2}}-1}
$$
}

where $R \in[0,1]$. 
can show that (a) $R_{t}$ decreases monotonically; (b) the economy fully modernizes (that is, $R_{t}$ converges to 0 ); and (c) it does so in more that one period (otherwise inequality remains at $\frac{\sigma}{\bar{w}}$ for all time); we will have shown that the economy follows the inverted-U curve as it develops. ${ }^{20}$

We note first that the level of migration (i.e. $R_{t}-R_{t+1}$ ), as shown in Figure 3 , is nonnegative - no one ever migrates from the city to the village. Thus $R_{t}$ does indeed follow a monotonic path.

$>$ From Figure 3, a lower bound for the level of migration is given by $R(\infty)-$ $R\left(a_{C}(\hat{r})\right)=R_{t}\left(1-F\left(\frac{a_{C}(\hat{r})}{\beta}\right)\right)$. Thus, if $\overline{\bar{w}}>\frac{a_{C}(\hat{r})}{\beta}$, there is a uniform positive lower bound on the fraction of the rural population that will migrate each period, and it follows that $R_{t}$ converges to zero.

Finally, we need to ensure that the economy does not modernize instantly. Note (again refer to Figure 3) that if the interest rate is $\hat{r}$ upon opening the urban sector, then not everyone migrates in the first period, except in the singular case in which $m\left[1-R\left(a_{C}(\hat{r})\right)\right]=\beta \bar{w}$. This is equivalent to the condition that $\frac{\beta \bar{w}}{m}>$ $1-F\left(\frac{a_{C}(\hat{r})}{\beta}\right) .{ }^{21}$ Thus we have

Proposition 4.1. If $\overline{\bar{w}}>\frac{a_{C}(\hat{r})}{\beta}, \underline{\underline{w}}>s$, and $\frac{\beta \bar{w}}{m}>1-F\left(\frac{a_{C}(\hat{r})}{\beta}\right)$, then as $t \rightarrow \infty$, $R_{t} \rightarrow 0$ (the economy fully modernizes) and the path of inequality and income follows an inverted- $U$ curve.

Notice that although the economy fully modernizes, it does so too slowly - even if full modernization takes only finite time, ${ }^{22}$ any discounted sum of single-period social surpluses would be increased if modernization were to occur immediately as the modern sector opens.

The modernization process in this example operates at two levels. When full modernization occurs, it is because some fraction of rural agents are always successful enough to pass on a large bequest to their children, who can then afford to insure themselves in the modern sector. This is an individual level effect

\footnotetext{
${ }^{20}$ Apparently, the idea that a monotonic increase in the urban population leads to this inverted- $U$ relation between income and the coefficient of variation is known (see [11]), although there the rate of migration is left unexplained.

${ }^{21}$ It is not hard to find distributions which satisfy this condition. Start with a mean wage $\bar{w}$ $>q s$ and the unit mass there. Choose $\beta$ small enough to render $\frac{a_{C}(\hat{r})}{\beta}>\bar{w}$. Now replace the unit mass with a uniform with mean $\bar{w}$ and support in $\left[q s, \frac{a_{C}(\hat{r})}{\beta}\right]$. Through mean-preserving spreads, generate a continuous distribution $G(w)$ with support equal to $\left[q s, \frac{a_{C}(\hat{r})}{\beta}\right]$. Since $G\left(\frac{a_{C}(\hat{r})}{\beta}\right)=1$, $\frac{\beta \bar{w}}{q m}>1-G\left(\frac{a_{C}(\hat{r})}{\beta}\right)$. Finally, let $F$ be a mean-preserving spread of $G$ which puts (a small) positive weight above $\frac{a_{C}(\hat{r})}{\beta}$, preserving the condition.

${ }^{22}$ For some parameter values, mean wealth might exceed $m$ in finite time, which as we have seen, then leads immediately to full modernization.
} 
which depends on primitive assumptions about the distribution of earnings. But there is also a "trickle-down" effect which operates at a more aggregate level: as people move to the city, they earn more so that aggregate wealth increases; meanwhile, demand for loans typically does not increase. This leads to a decrease in the interest rate, which relaxes the borrowing constraints for everyone. More generally, the agency costs of borrowing in the city are reduced at the lowered interest rate (in this case reflected by the fall in $a_{C}(r)$ ), which in turn make the modern sector attractive to more people. A related trickle-down mechanism is discussed in [2]

In a parallel way, increasing wealth in the modern sector reduces the effects of poor information there. For an individual, having a lot of wealth improves his borrowing prospects. And as the whole economy becomes wealthy, falling interest rates lower the agency costs of borrowing for everybody. Thus, there is a dual sense in which a wealthy economy can afford to do without good information.

\subsection{Undermigration in the Long Run}

What if the conditions of Proposition 4.1 are not satisfied? Is it possible that a long-run version of undermigration can occur, i.e. that the economy could settle into a steady state in which some people inefficiently remain in the rural sector?

If the economy were to get stuck in an undermigration trap, both the individual and trickle-down effects would have to be mitigated. We first begin by dispensing with the assumption that $\overline{\bar{w}}>\frac{a_{C}(\hat{r})}{\beta}$, which weakens the first effect, and is necessary if there is not to be full modernization; thus $\overline{\bar{w}} \leq \frac{a_{C}(\hat{r})}{\beta}$ and $F\left(\frac{a_{C}(\hat{r})}{\beta}\right)=1$. We continue to assume that $\beta \bar{w}<m$, as this is also a necessary condition for undermigration, as discussed above.

We shall be interested in deriving the recursion function for the state variable $R_{t}$, the rural population at the beginning of the period $t$. Denoting the current interest rate by $r_{t}$, the rural population evolves according to:

$$
R_{t+1}=G\left(R_{t}\right)= \begin{cases}R_{t} F\left(\frac{a_{C}\left(r_{t}\right)}{\beta}\right), & r_{t}<\hat{r} \\ \frac{\beta \bar{w}}{m}\left[R_{t}+\left(1-R_{t}\right) \lambda\right]-\left(1-R_{t}\right)\left(1-F\left(\frac{a_{C}\left(r_{t}\right)}{\lambda \beta}\right)\right), & r_{t}=\hat{r} \\ 0, & r_{t}>\hat{r}\end{cases}
$$

Of course, this is not yet a proper characterization of dynamics, because $r_{t}$ itself depends on $R_{t}$ through the loan market equilibrium. This equilibrium can be characterized very simply, however. The supply of loans each period is $\beta \bar{w}\left[R_{t}+\right.$ $\left.\left(1-R_{t}\right) \lambda\right]$. Demand is 


$$
\begin{array}{ll}
m\left[1-\left(1-R_{t}\right) F\left(\frac{a_{C}\left(r_{t}\right)}{\lambda \beta}\right)\right], & r_{t}<\hat{r} \\
{\left[m\left(1-R_{t}\right)\left\{1-F\left(\frac{a_{C}\left(r_{t}\right)}{\lambda \beta}\right)\right\}, m\left\{1-\left(1-R_{t}\right) F\left(\frac{a_{C}\left(r_{t}\right)}{\lambda \beta}\right)\right\}\right]} & r_{t}=\hat{r} \\
m\left(1-R_{t}\right)\left[1-F\left(\frac{a_{C}\left(r_{t}\right)}{\lambda \beta}\right)\right], & r_{t}>\hat{r}
\end{array}
$$

$>$ From these expressions, one can verify that $r$ is increasing in $R$ when $r_{t}<\hat{r}$.

Now observe that for all $R \in[0,1], G(R) \leq R$, since migration never goes from city to village. Since $G(R) \geq 0$ by definition, we conclude that $G(0)=0$.

We now need to establish the existence of the fixed points of $G(\cdot)$ other than zero. At any such be such a fixed point, the associated interest rate $r^{*}$ must satisfy $F\left(\frac{a_{C}\left(r^{*}\right)}{\beta}\right)=1$ and $r^{*} \leq \hat{r}$. Suppose there is a fixed point (call it $\bar{R}$ ) associated with the interest rate $\hat{r}$. As this is a stationary point, there can be no migration when $R=\bar{R}$. Therefore, supply must be equated to the highest level of demand generated by $\hat{r}$ (refer back to Figures 2 and 3 ) and we have

$$
\beta \bar{w}[\bar{R}+(1-\bar{R}) \lambda]=m\left[1-(1-\bar{R}) F\left(\frac{a_{C}(\hat{r})}{\lambda \beta}\right)\right]
$$

Now choose $R^{*}$ below $\bar{R}$. The corresponding equilibrium interest rate $r^{*}$ must also lie below $\hat{r}$ (supply increases while demand decreases). So long as $F\left(\frac{a_{C}\left(r^{*}\right)}{\beta}\right)=$ $1, R^{*}$ is also a fixed point of $G(\cdot)$. Indeed, there will be an interval (possibly degenerate) of fixed points $[\underline{R}, \bar{R}]$, where the interest rate $\underline{r}$ associated with $\underline{R}$ satisfies $a_{C}(\underline{r})=\beta \overline{\bar{w}}$. Thus we need only establish the existence of a nonzero solution to (4.2) in order to guarantee that $G(\cdot)$ has stationary points bounded away from zero. ${ }^{23}$

Solving (4.2) for $\bar{R}$ yields

$$
\bar{R}=\frac{\frac{\lambda \beta \bar{w}}{m}+F\left(\frac{a_{C}(\hat{r})}{\lambda \beta}\right)-1}{\frac{(\lambda-1) \beta \bar{w}}{m}+F\left(\frac{a_{C}(\hat{r})}{\lambda \beta}\right)}
$$

this expression lies in the allowable range if and only if $\frac{\lambda \beta \bar{w}}{m}+F\left(\frac{a_{C}(\hat{r})}{\lambda \beta}\right)-1>0$. It is not hard to find parameter values for which this condition holds. Thus we have Proposition 4.2. Suppose that $\frac{\lambda \beta \bar{w}}{m}+F\left(\frac{a_{C}(\hat{r})}{\lambda \beta}\right)-1>0$. Then there exists an interval $[\underline{R}, \bar{R}]$ of rural population levels which remain constant over time once the economy arrives there.

\footnotetext{
${ }^{23}$ For $R>\vec{R}$, the interest rate remains at $\hat{r}$. Raising $R$ decreases supply and raises the upper bound of demand at $\hat{r}$, so the interest rate cannot fall. On the other hand, if $r$ rises, it must satisfy

$$
q m(1-R)\left[1-F\left(\frac{a_{C}(r)}{\lambda \beta}\right)\right]=\beta \bar{w}[R+(1-R) \lambda]
$$

solutions to this equation are decreasing in $R$, a contradiction.
} 
Since $\bar{R}>0$, at least some of these levels are positive: full modernization does not occur. We therefore refer to the interval $[\underline{R}, \bar{R}]$ as the "undermigration trap."

How might the economy actually arrive in an undermigration trap? We could start by returning to our original question and asking whether long-run undermigration is possible starting from a pure rural economy. Figure 4 illustrates possible shapes that $G(R)$ might assume, given that the undermigration trap exists. As noted in footnote 23 above, when $R \geq \bar{R}$, the interest rate is $\hat{r}$. Thus, $G(R)$ is linear there and can have either slope, depending on the sign of $\frac{\beta \bar{w}}{m}(1-\lambda)+1-F\left(\frac{a_{C}(\hat{r})}{\lambda \beta}\right)$. If the slope is positive (Figure $4(\mathrm{a})$ ), then an economy starting at $R=1$ will converge to $\bar{R}$; income inequality will increase over time, perhaps decreasing a small amount toward the end (the so-called inverted J-curve).

But for most parameter values the slope will be negative (see Figure 4(b)). Thus the only way a pure rural economy would fall into the undermigration trap is if $G(1)=\frac{\beta \bar{w}}{m} \geq \underline{R}$ : as shown in Figure $4(\mathrm{~b})$, when this condition is satisfied, the economy jumps to the undermigration trap as soon as the urban sector opens. If this condition fails, the economy jumps past the undermigration trap when the urban sector opens and then eventually fully modernizes (Figure 4(c)). In these cases, trickle-down remains strong enough to eventually modernize the economy.

We have been asking whether long run undermigration is possible assuming that the economy starts out purely rural. This is a useful thought experiment, but is not necessarily the only relevant case. Many instances of modernization and development, especially in modern times, correspond to opening an already large urban sector to the rural sector. Thus initial conditions with $R<1$ are also of interest. As indicated in Figure 4(c), the basin of attraction of the undermigration trap is considerably larger than the trap itself, so a failure to modernize is reasonably likely: if the economy begins with the size of the rural sector in the interval $[\underline{R}, \bar{R}]$, it falls into the trap. We therefore have a dynamic analogue to the conditions leading to undermigration in the static case discussed in the previous section. Opening a moderate-sized city to the village may not effect further development of the economy, at least if one relies on the laissez-faire migration mechanism.

\subsection{Other Dynamics with Self-Selection}

As we stated at the outset, there has been considerable controversy surrounding the validity of the Kuznets hypothesis. We have seen that it is possible for the migratory dynamics generated by the trade-off between high modern sector productivity and efficient traditional sector institutions to yield an inverted-U curve. What we show now, is that even if we maintain the same basic "engine" of modernization that Kuznets and his followers described, it is possible under plausible 
specifications to generate rather different patterns for the evolution of inequality. In particular, the way individuals select for migration will be crucial.

Suppose that agents learn the level of their earnings at birth, before they make their location decision. Assume this information is public. Then each period, migration follows the pattern described by Proposition 3.1 and Figure 1. In particular, note that low-skill agents migrate while medium-skill agents remain in the rural sector. Imagine that the low-skilled in the city actually end up earning close to what the medium-skilled are earning back in the village. Then, assuming the fraction of very high-skill agents (those who migrate even though they could get loans in the rural sector) is small, the possibility arises that opening the urban sector could actually decrease the level of inequality; subsequently, as the rural sector empties out, inequality increases again. The result is an "upright" $U$, rather than Kuznets's inverted U. In the appendix, we analyze a specific example which generates this and other patterns of the evolution of inequality.

The implications of the dynamic examples in this section may be summarized by saying that the characteristics of those who choose to migrate may have important implications for the evolution of inequality in developing countries. Moreover, as the example there shows, the dynamics of inequality can depend delicately on the parameters of the distribution of these characteristics. In addition, as a comparison with the results Sections 4.1 and 4.2 reveals, seemingly irrelevant changes in the timing of location decisions can have a dramatic impact on the evolution of the aggregate variables. We conclude that there is no broad theoretical reason - even if we adhere to a sectoral shifting story of development - to believe in the universality of the inverted $\mathrm{U}$.

\section{Discussion}

The model in this paper, while suggestive in several respects, leaves out much to be a useful predictive model of the process of modernization. Some of these omitted factors, such as congestion effects in the modern sector and the fact that one does not get completely cut off from the traditional sector when one first starts working in the modern sector, go against our results. Others, like the fact that the ability of the traditional sector to provide better loans or insurance may depend on how many people are left in the traditional sector, may reinforce our results. A truly predictive model of the process of modernization must build in all of these effects. 


\subsection{Overmigration?}

One possibility which we have not so far discussed is that of overmigration, according to many a major problem in many countries today. In the present model, overmigration exists when the aggregate wealth $\bar{a}$ is less than $m$, but the loan market fails to clear, i.e. even at an interest rate of unity there is more wealth than is demanded for youthful consumption. Now, while this won't be possible under laissez-faire (if $r=1$, anyone who moved to the city who doesn't have a loan there would be better off staying in his village; the wealth would flow to him there, and condition (3.1) implies he would be better off), it is possible that catastrophes such as the Bengal famine in the 1940's would have the effect of forcing sudden movement to the city with concomitant dissolution of the rural information networks. Suppose that the condition $\frac{\bar{a}}{m}>1-R\left(a_{C}(1)\right)-U\left(a_{C}(1)\right)$ mentioned in the proof of Proposition 3.2 holds. Then we would have a situation in which everyone (say) was in the city, but a fair amount of them (more than is necessary given the amount of wealth in the economy) were unable to borrow so that much of the economy's wealth would be "idle," i.e., consumed rather than used for school. Thus, while forced migration might have desirable consequences if there are not too many villagers who are poor (have wealth less than $a_{C}(1)$ ), the opposite may be true if there are too many of them; an optimum would then involve keeping some of those people in the rural sector. ${ }^{24}$

\subsection{Alternate Assumptions about Capital Flows}

A different sort of possibility arises when we drop the assumption that wealth is free to flow between the village and the city. It has frequently been argued that capital formation in developing countries is inhibited by its inability to flow across sectors. Policies have often been designed to try to encourage intersectoral mobility of resources. Without going into details on the effects of closing the "national" capital market on the level of migration (it could be higher or lower, depending on parameters, but as in the case we have been considering, will generally not result in instantaneous full modernization), we will focus on what it says about the nature of the inefficiency in our model.

Supposing then that wealth cannot freely flow between sectors, the principal effect is that the argument for static inefficiency no longer applies: while forcing everyone into the modern sector would continue to result in increased output, the capital would no longer follow them to the city. Thus, under laissez-faire, the

\footnotetext{
${ }^{24}$ The optimal allocations of people across sectors are the those used in the proof of Proposition 2. Of course, this discussion presupposes that interventions in the loan market or direct redistributions of wealth are not possible.
} 
rate of modernization, although not instantaneous (individuals face a trade-off between high productivity and credit availability), could not be considered to be inefficient in the sense we have been considering: only if capital were somehow forced into the modern sector along with the individuals could a surplus gain be achieved.

To see this explicitly, take the extreme case in which the capital is stuck in each location at whatever amounts are there initially. In equilibrium there will be two interest rates, one for each location. Call them $r_{V}$ and $r_{C}$ (we cannot say which is higher, in general). All villagers with wealth below $a_{V}\left(r_{V}\right)$ and above $a_{C}\left(r_{C}\right)$ will migrate. Forcing those who remain to move to the city will not affect the urban interest rate (since demand falls in the village, the interest rate would fall there, but this doesn't help anyone because everyone who had been there before was getting a loan) because no capital can flow there and the new arrivals don't have an effective demand because their wealth lies below $a_{C}\left(r_{C}\right)$. The new arrivals must be worse off (since they had chosen not to move in the equilibrium and their options in the city are no different), so total surplus must decline.

This situation parallels the one in which life in the village has some consumption value that is unavailable in the city (scenery, for instance). In this standard hedonic pricing setting, agents locate in one sector or the other depending on their tastes for scenery; the resulting allocation is efficient. Thus, it is the ability of wealth to flow between the sectors that generates the static inefficiency in our model. $^{25}$

But there is a difference between the case of wealth and that of scenery: ${ }^{26}$ next period's capital can effectively be brought to the city, while next period's scenery cannot. Once everyone is forced into the urban sector, they will generate more wealth for the ensuing period than they would have under laissez faire. Since capital market clearing within the urban sector entails that all of this wealth be used for loans, surplus will be higher in the second period than it would be without forced migration. Therefore, when wealth cannot flow across the two sectors, "the static economy is efficient, but the dynamic economy may remain inefficient.

\subsection{Implications for Rural Lending Institutions}

At first blush, our results might suggest that policies designed to encourage the availability of credit in the traditional sector may be misguided. Certainly, arbitrary ones designed simply to ease the flows of capital between rural and urban

\footnotetext{
${ }^{25}$ This is not to say that the laissez-faire surplus generated when capital can flow is smaller than it is when capital cannot (again, it can go either way). But in the former case, it is not as large as it could be, given the constraints on information and resource flow, while in the second case, it is.

${ }^{26}$ Beside the one that the capital market is imperfect within the two locations.
} 
moneylenders might serve to retard rate of modernization. But what the forgoing discussion on capital flows (and the analysis more generally) should make clear is that the effects of changes in the quality of the rural institution depend critically on how economy wide cost of capital is affected. Policies designed to ease access to credit in the rural sector should be implemented bearing in mind what the social opportunity cost of capital is, and more particularly in conjunction with policies designed to elicit greater availability of capital, e.g. saving subsidies or foreign aid.

To see this somewhat more precisely, imagine that the village begins with a (small) positive value of $\pi$ and that a policy is introduced which has the effect of lowering it, say to 0 . Imagine at the same time that there is no change in aggregate wealth (nothing is done either to elicit more saving within the economy or to obtain capital from abroad). The initial impact is that $a_{V}$ falls, so fewer people will migrate to the city: the "bottom" of the middle class remaining in the village expands.. Since this typically results in a greater demand for loans, the interest rate will rise, which raises $a_{C}$; this means that the "top" of the middle class expands as well (of course, the rising interest rate causes $a_{V}$ to rise again, but it is easy to show that it cannot rise above its old level). ${ }^{27}$ The net effect is a decrease in migration and a slowdown in the rate of modernization.

Notice this argument depends crucially on the interest-rate increasing effect of the rural lending program. This can be mitigated in several ways. In practice, programs such as Grameen bank tend to rely on foreign aid and other sources of funding that come from outside the economy and which therefore are unlikely to affect the capital market within the country very much: if the capital were not funneled to poor women, it probably would not go to more productive uses in Bangladesh. Indeed, the success of these programs in attracting capital from abroad is at least as important as their ability to channel that wealth to targeted groups. (Observe that if we trace the effects of the decrease in $\pi$ without a concomitant rise in the interest rate, the effects are unambiguously welfare enhancing: the people who are now getting loans are better off - they could still migrate without a loan if they chose-while absent the pecuniary externality generated by

${ }^{27}$ To see this, denote by $\bar{a}_{V}(r)$ the village threshold wealth with the lower value of $\pi$; note that $\bar{a}_{V}(r)<a_{V}(r)$ for each $r$. Let the old interest rate be $r_{0}$ and the new one $r_{1}$. The new market clearing equation which determines $r_{1}$ is

$$
1-U\left(a_{C}\left(r_{1}\right)\right)-R\left(\bar{a}_{V}\left(r_{1}\right)\right)=\frac{\bar{a}}{m} ;
$$

therefore $r_{1}>r_{0}$ (as long as $U(\cdot)$ and $R(\cdot)$ are strictly increasing). Thus $U\left(a_{C}\left(r_{1}\right)\right)>U\left(a_{C}\left(r_{0}\right)\right)$, from which it follows, using the market clearing equations, that $R\left(\bar{a}_{V}\left(r_{1}\right)\right)<R\left(a_{V}\left(r_{0}\right)\right)$. Note this implies that the new level of migration, $R(\infty)-\left[R\left(a_{C}\left(r_{1}\right)\right)-R\left(\bar{a}_{V}\left(r_{1}\right)\right)\right]$ is lower than the old one. 
changes in $r$, there is no effect on anyone else.) Alternatively, if the interest elasticity of saving is high, the effects we have outlined will also be mitigated. More generally, policies which encourage savings will be most effective when it can be ensured that the capital thus generated will actually reach potential borrowers.

A similar point pertains to the evaluation of programs designed to promote rural industry. If loans in our model were for production rather than consumption, the effects would be similar: there could be too much production in the rural sector, and modernization could too slow. A rural industry which is growing rapidly may not be a socially desirable target for investment: high growth might reflect credit availability (because of local information networks) rather than high social returns.

The point is that just as we should not be trying to understand the institutions of an economy in isolation from one another, we cannot think sensibly about policies in isolation from one another: programs designed to channel credit to targeted groups must be accompanied by programs designed to raise this credit from low cost sources, lest they do more harm than good. Poor countries don't need only to get wealth to poor people; they also need more wealth.

\section{Appendix: Violations of the Inverted U}

Suppose that there are just two skill levels, $w$ and $\lambda w$ (these are the earnings of an agent in the village; in the city he would earn $\lambda w$ and $\lambda^{2} w$ ). An agent's chance of having the high skill is $\chi$, assumed independent of the wealth he inherits. Make the following parametric assumptions:

$$
\begin{gathered}
(\lambda+\beta) w>s-(\lambda-1) \lambda w \\
(s-m)>(\lambda-1) \lambda w \\
\beta w>m-\frac{\lambda w m}{s-(\lambda-1) \lambda w} \\
m-w>\lambda \beta w
\end{gathered}
$$

Assumption (6.1) ensures that high-skill agents in the rural sector can repay loans at date 1 when the interest rate is $\hat{r}(\lambda w) ;(6.2)$ is the analog of $(3.1)$ and ensures that inefficient undermigration is possible; (6.3) implies that the high-skill agents always have enough wealth to obtain a loan (i.e., their wealth, which is at least $\beta w$, exceeds $\left.a_{V}(\lambda w, \hat{r})\right)$, while (6.4) ensures that the low-skill agents are below $a_{V}(w, 1)$ and therefore always migrate. ${ }^{28}$ Figure 5 , which is just Figure 1 specialized to the

\footnotetext{
${ }^{28} \mathrm{It}$ is not difficult to find parameters satisfying (6.1)-(6.4). For instance, $\lambda=2, w=1$, $q=0.5, m=3, s=8, \beta=0.2$.
} 
current example, depicts the possible wealth-wage combinations that can occur as the economy evolves. Before the modern sector opens, wages are either $w$ or $\lambda w$, and wealth always lies somewhere below $\beta \lambda w$ (so wealth-wage pairs lie on the heavy segments). ${ }^{29}$ Note that by choosing $\pi_{C}$ sufficiently close to 1 , one can guarantee that the high-skill agents born in the village will be unable to obtain loans in the city (i.e., their wealth will lie below $a_{C}(\lambda w, r)$ for all $\left.r\right)$.

Assumption (6.4) ensures that as long as some of the population remains in the rural sector, a positive fraction $\chi$ of their children will be born poor and low-skilled enough to migrate. Eventually, therefore, the economy fully modernizes. Observe that in this example, in contrast to those considered in the previous subsections, it is the low types who migrate; modernization comes from below rather than above (more generally, as we have pointed out, it tends to come from the tails of the distribution, not the middle).

In any period, only two wages are earned: either $w$ and $\lambda w$ or $\lambda w$ and $\lambda^{2} w$. Thus, if $\rho$ is the fraction of the population earning the higher wage, the coefficient of variation is $\frac{\sqrt{\rho(1-\rho)}(\lambda-1)}{\rho \lambda+1-\rho}$, which achieves a unique maximum at $\rho=\frac{1}{\lambda+1}$. The initial distribution of wages has $\chi$ at $\lambda w$ and $1-\chi$ at $w$; since there is full modernization, eventually the distribution approaches $\chi$ at $\lambda^{2} w$ and $1-\chi$ at $\lambda w$. Thus, inequality is the same at the start and end of the development process.

Now consider the periods in between. As the urban sector opens, the low-skill agents migrate to the city, where they earn $\lambda w$. They pass on bequests of $\beta \lambda w$; their children will earn either $\lambda w$ or $\lambda^{2} w$, bequeathing $\beta \lambda w$ and $\beta \lambda^{2} w$. Meanwhile, the children of the high-skilled agents who remain in the village inherit wealth $\beta \lambda w$ and skill $w$ or $\lambda w$. From these considerations, there are five possible wealthwage pairs that can occur once the modern sector is opened (but before location choices are made); these are denoted by the X's in Figure 5.

For certain levels of $\chi,^{30}$ market clearing entails that $r=\hat{r}(\lambda w)$ and that some (call the fraction $\tau$ ) of the high-skill agents also migrate (the demand and supply functions for this case are shown in Figure 6). ${ }^{31}$ Suppose that $\chi=\frac{1}{\lambda+1}$ (or nearly

${ }^{29}$ Without actually calculating any particular distribution of wealth - such as a steady state - for the pure rural economy (unlike in sections 4.1 and 4.2 , this computation is complicated by the fact that under the parametric assumptions (6.1)-(6.4), at interest rates larger than $\hat{r}(\lambda w)$, loans cannot necessarily be repaid out of date-3 earnings alone), it is not hard to verify that an upper bound for any agent's wealth is $\beta \lambda w$, since from what we said at the beginning of the section, $\lambda w$ is the most that an agent would have at date 4 from which to produce a bequest.

${ }^{30}$ Specifically, maximum demand at $\hat{r}(\lambda w), \chi q m$, must exced supply $[\chi \lambda+1-\chi] \beta w$; using (6.4), this is equivalent to

$$
\chi>\frac{\beta w}{q m-(\lambda-1) \beta w} .
$$

${ }^{31}$ The figure is drawn supposing that there are just two wealth levels at the time the city opens; 
so); after the urban sector opens we have $\chi \tau$ at $\lambda^{2} w$ and $1-\chi \tau$ at $\lambda w$. Since $\chi=\frac{1}{\lambda+1}$ yields the maximum level of inequality, we find that in this case that the initial impact of the development process is to decrease inequality.

As before, let $R_{t}$ denote the beginning-of-period- $t$ rural population. As $t$ increases, $R_{t}$ decreases monotonically to zero; the supply of wealth is therefore increasing. Demand, meanwhile, cannot increase above its maximum initial level $\chi m$, since only high-skill agents (whether rural or urban) can exceed the respective threshold wealth levels. Therefore, interest rates cannot increase over time. If the interest rate in some period $t$ is less than $\hat{r}(\lambda w)$, the fraction of the population earning the high wage is $\chi\left(1-R_{t}\right)$, which increases with time. With $\chi=\frac{1}{\lambda+1}$, this implies that inequality must increase over time as well. ${ }^{32}$ In the limit as the economy evolves toward full modernization, inequality returns to its initial level: the path of inequality follows an upright $U$, contrary to Kuznets's hypothesis.

Essentially the same conclusion holds if initially market clearing occurs at $r=1$ (i.e., when $\chi$ fails to satisfy condition (6.5)), in which case none of the high-skill migrate in the first period. Then everyone earns $\lambda w$ : there is perfect equality $(\rho=0)$ as soon as the modern sector opens. Then a similar argument gives us a monotonic increase of $\rho$ back to its initial level. Inequality then traces out an upright $\mathrm{U}$, at least if $\lambda \beta<1$. $^{33}$

For other values of $\chi$, however, the initial impact of opening the modern sector can lead to an increase in inequality, à la Kuznets. To take an extreme example, suppose that $\chi$ is nearly equal to 1 (so there is nearly perfect equality to begin with). Then the interest rate following the opening of the modern sector will be $\hat{r}(\lambda w)$. A large fraction of the rural population migrates and earns the high wage $\lambda^{2} w$ : inequality has increased. ${ }^{34}$ Eventually, of course, everyone will end up in the city, so inequality will have to decline to its original level, yielding the inverted $U$.

the key point is that a finite number is typical. Readers may be bothered by the discontinuity in the demand which results from the atoms in the wage distribution. If instead the distribution was atomless and supported on two small intervals centered about $w$ and $\lambda w$, then demand would be continuous and the interest rates would always assume values very close to $\hat{r}, r_{1}$, and $r_{2}$ depicted in the diagram. The present example can be thought of as an approximation to that case. (Of course, by (6.4) $r_{1}$ and $r_{2}$ are less than 1 , so equilibrium always exists in the first period after the city opens; but the approximation is valid more generally.)

${ }^{32}$ In case $r$ remains at $\hat{r}(\lambda w)$, the fraction of high wage earners is still increasing over time, but the argument is slightly more complicated, and we omit it.

${ }^{33}$ If not, then if $\chi>\frac{1}{\lambda+1}$, inequality will overshoot its final (and original) level before declining back to it, thereby following a "sleeping S."

${ }^{34}$ With $\chi$ close to 1 , the fraction of the population which migrates and receives $\lambda^{2} w$ upon the opening of the modern sector is close to $1-\lambda \frac{\beta w}{q m}$; using $(6.4)$, this exceeds $\frac{1}{1+\lambda}$. Noting that inequality is decreasing on $\left[\frac{1}{1+\lambda}, 1\right]$ proves the claim. 


\section{References}

[1] Adelman, I. and S. Robinson (1989), "Income Distribution and Development," ch. 19 in H. Chenery and T.N. Srinivasan, eds., Handbook of Development Economics, vol. II.

[2] Aghion, P. and P. Bolton (1997), "A Theory of Trickle-Down Growth and Development," Review of Economic Studies.

[3] Anand, S. and S.M.R. Kanbur (1993), "The Kuznets Process and the Inequality-Development Relationship," Journal of Development Economics, 40:25-52.

[4] Banerjee, A.V., T. Besley and T. Guinnane (1994), "Thy Neighbor's Keeper: the Design of a Credit Cooperative with Theory and a Test," Quarterly Journal of Economics, CIX: 491-516.

[5] Banerjee, A. V. and A. F. Newman (1993), "Occupational Choice and the Process of Development," Journal of Political Economy, 101: 274-298.

[6] Baumol, W. J. (1990), "Entrepreneurship: Productive, Unproductive, and Destructive," Journal of Political Economy, 98: 893-921.

[7] Bernhardt, D. and H. Lloyd-Ellis (1993), "Enterprise, Inequality, and Economic Development," Queens University D.P. \#893.

[8] Bloom, D. E. and O. Stark (1985), "The New Economics of Labor Migration," American Economic Review Papers and Proceedings, 173-178.

[9] Das Gupta, M. (1987), "Informal Security Mechanisms and Population Retention in Rural India," Economic Development and Cultural Change, 36: 101-120.

[10] Fei, J. and G. Ranis (1964), Development of the Labor Surplus Economy: Theory and Policy, Homewood, Mlinois: Irwin.

[11] Fields, G. S. (1980), Poverty, Inequality, and Development, Cambridge: Cambridge Univerity Press.

[12] ___ (1992), "The Kuznets Curve: A Good Idea But...," mimeo, Cornell University.

[13] Glomm, G. and Ravikumar (1994), "Public versus Private Investment in Human Capital: Endogenous Growth and Income Inequality," Journal of Political Economy, 100: 818-834. 
[14] Harris, J. and M. P. Todaro (1969), "Migration, Uniemployment, and Development: a Two-Sector Analysis," American Economic Review 59: 126-142.

[15] Kehoe, T. and D. K. Levine (1993), "Debt-Constrained Asset Markets," Review of Economic Studies.

[16] Kuznets, S. (1955), "Economic Growth and Income Inequality," American Economic Review 45: 1-28.

[17] Lewis, W.A. (1954), "Economic Development with Unlimited Supplies of Labor," The Manchester School 22: 139-91.

[18] Mokyr, J. (1990), The Lever of Riches, Oxford: Oxford University Press.

[19] North, D. and R.P. Thomas (1972), The Rise of the Western World: A New Economic History, Cambridge: Cambridge University Press.

[20] Putnam, R.D. (1993), Making Democracy Work, Princeton: Princeton University Press.

[21] Rosenberg, N. and L.E. Birdzell (1986), How the West Grew Rich, New York: Basic Books.

[22] Sen, A. K. (1966), "Peasants and Dualism with or without Labor Surplus," Journal of Political Economy 74: 425-450.

[23] Stark, O. (1991), The Migration of Labor, London: Basil Blackwell.

[24] Stiglitz, J. (1990), "Peer Monitoring and Credit Markets," World Bank Eco-. nomic Review, 351-366.

[25] Townsend, R. (1994), "Risk and Insurance in Village India," Econometrica, $62(3): 539-592$.

[26] Udry, C. (1994), "Risk and Insurance in a Rural Credit Market: An Empirical Investigation in Northern Nigeria" Review of Economic Studies, 61 (3): 495526.

[27] Varian, H. (1990), "Monitoring Agents with Other Agents," Journal of Institutional and Theoretical Economics, 153-174.

[28] Williamson, J.G. (1988), "Migration and Urbanization", in H. Chenery and T.N. Srinivasan (ed) Handbook of Development Economics, North Holland, Amserdam. 


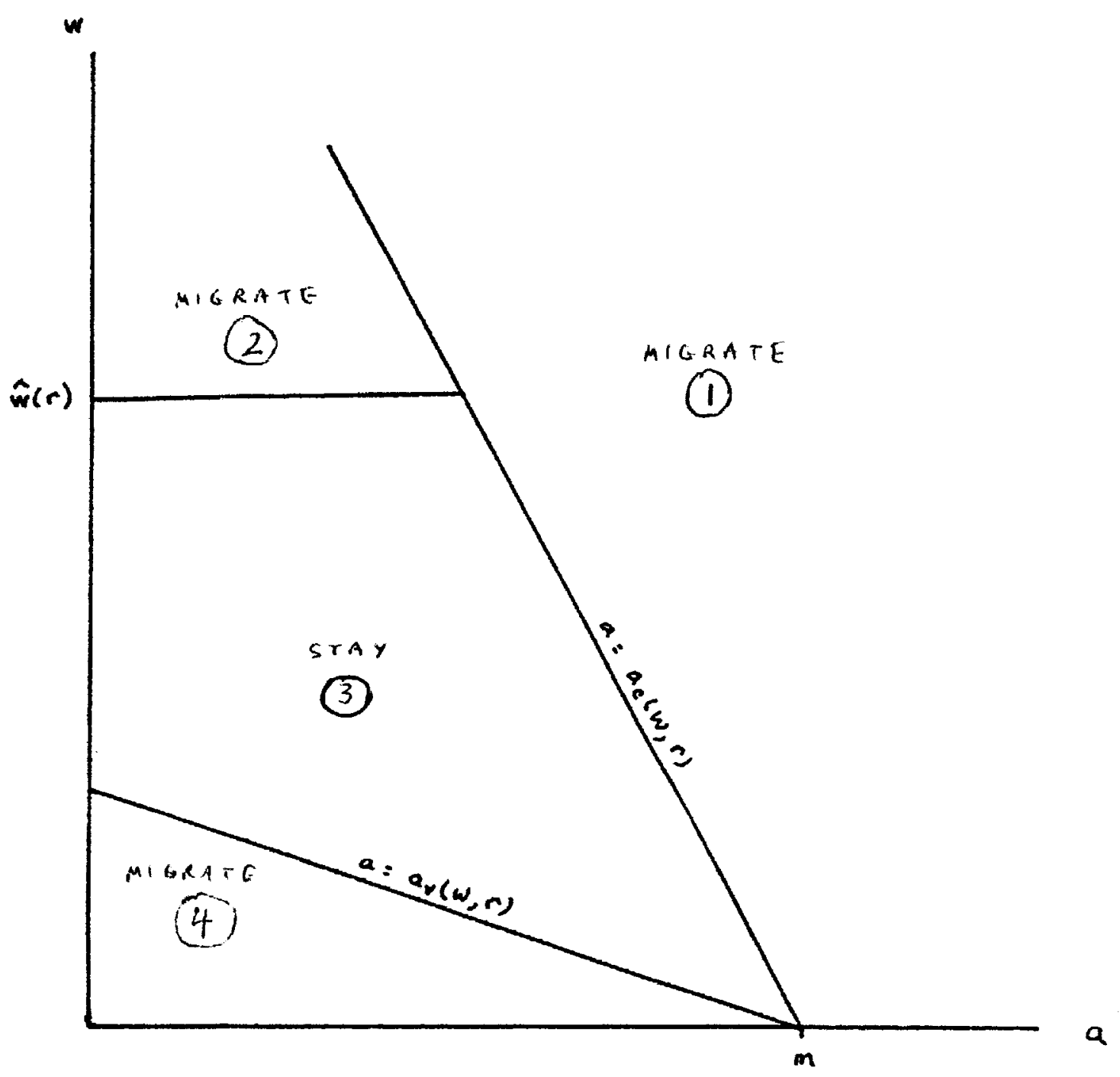

Agents in regions (1) and (3) consume in youth; those in (2) and $(2$ do not Figure 1 


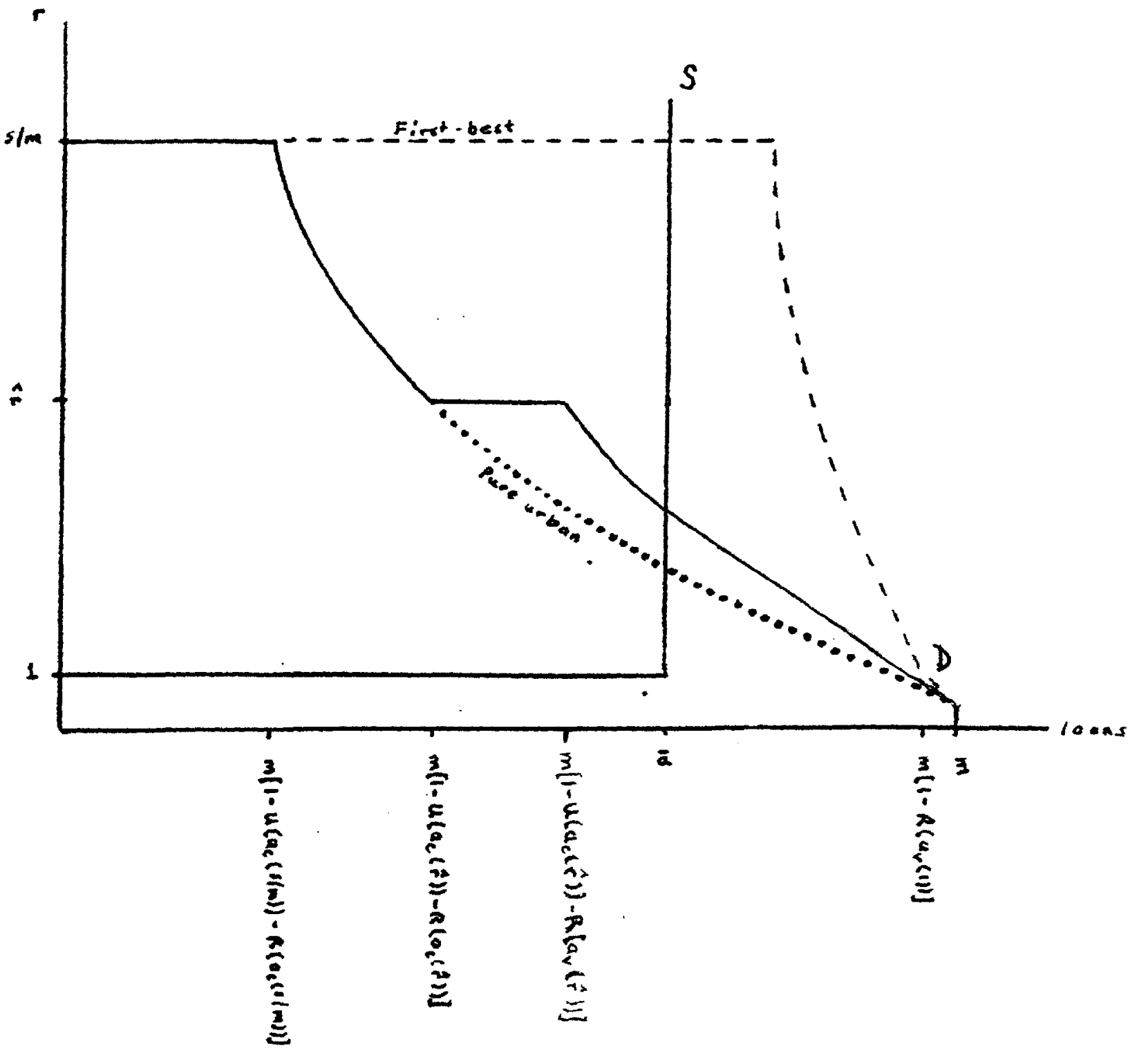

Figure 2

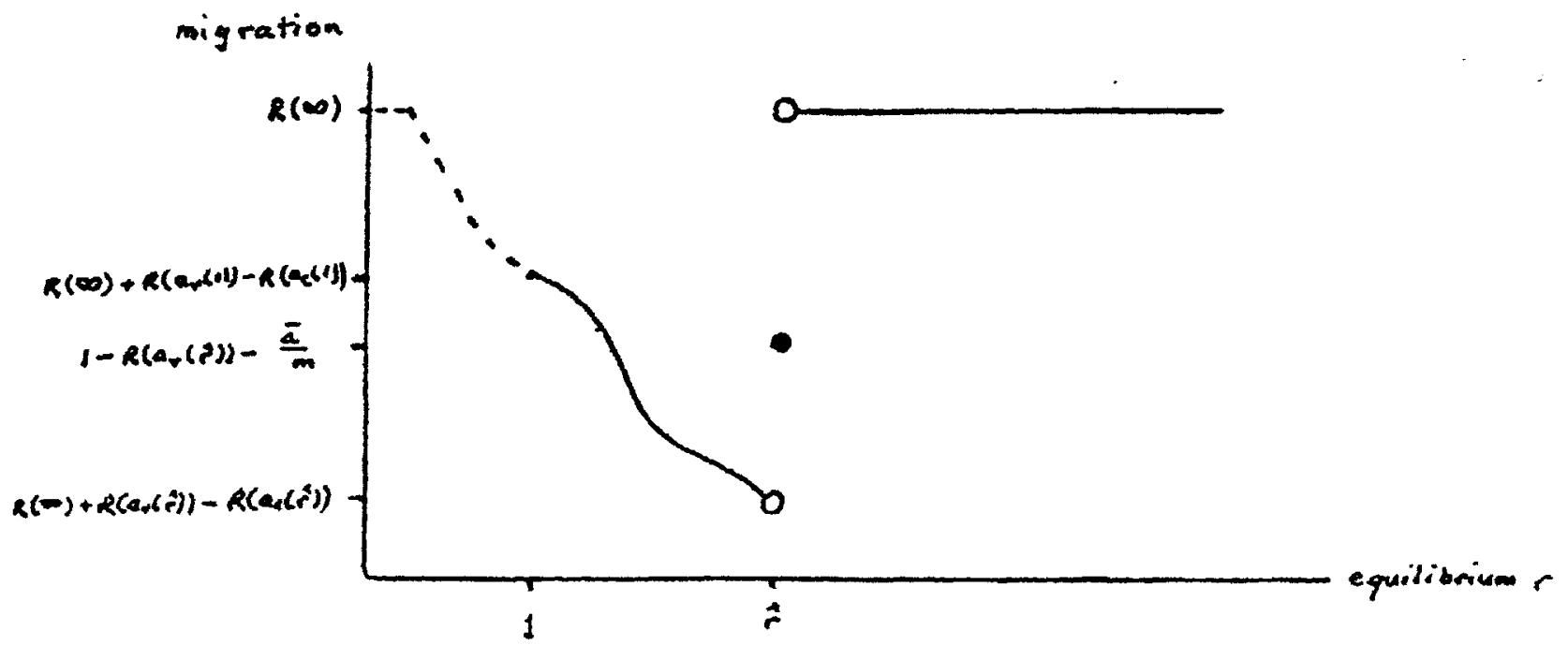

Figure 3 


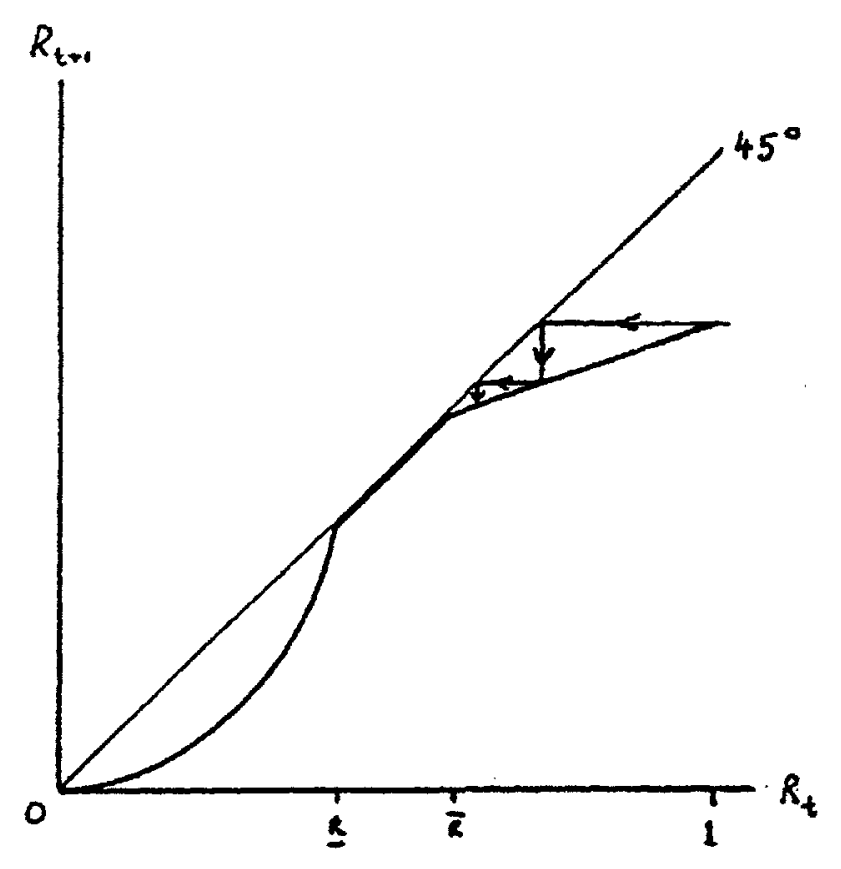

(a)

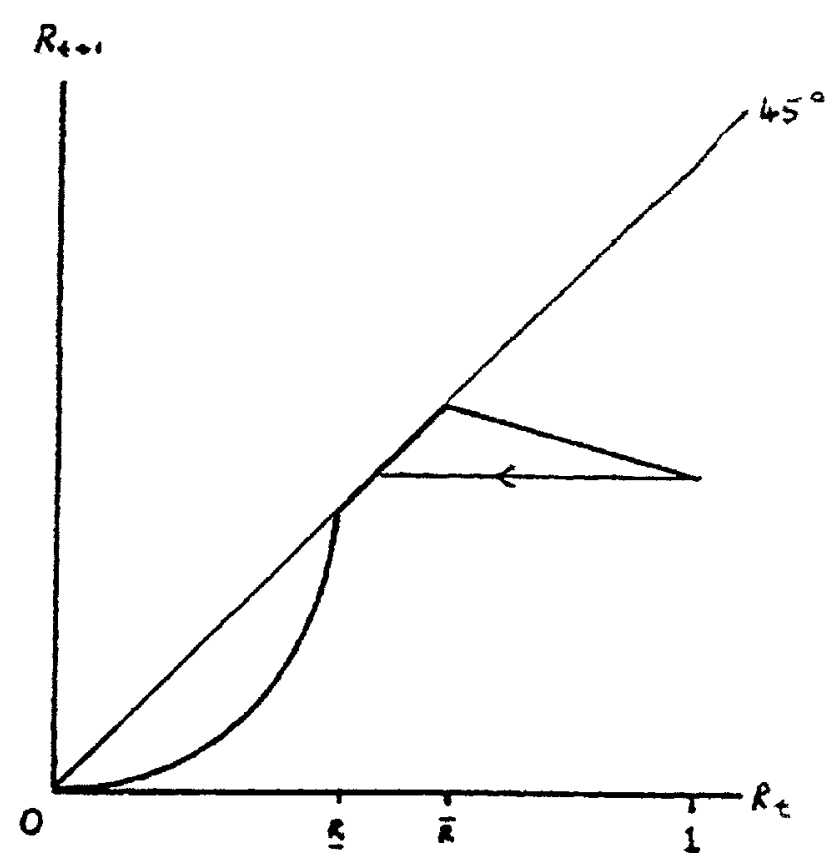

(b)

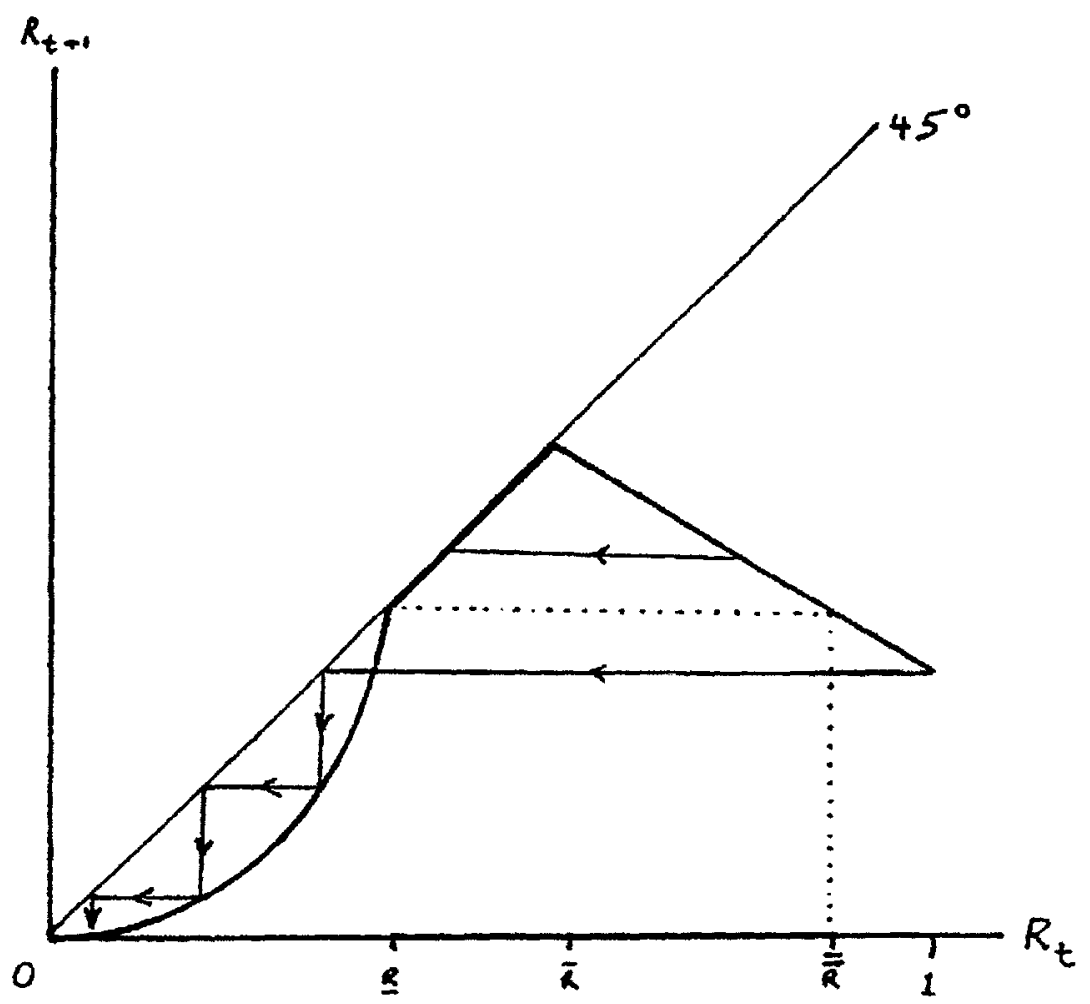

(c)

Figure 4 


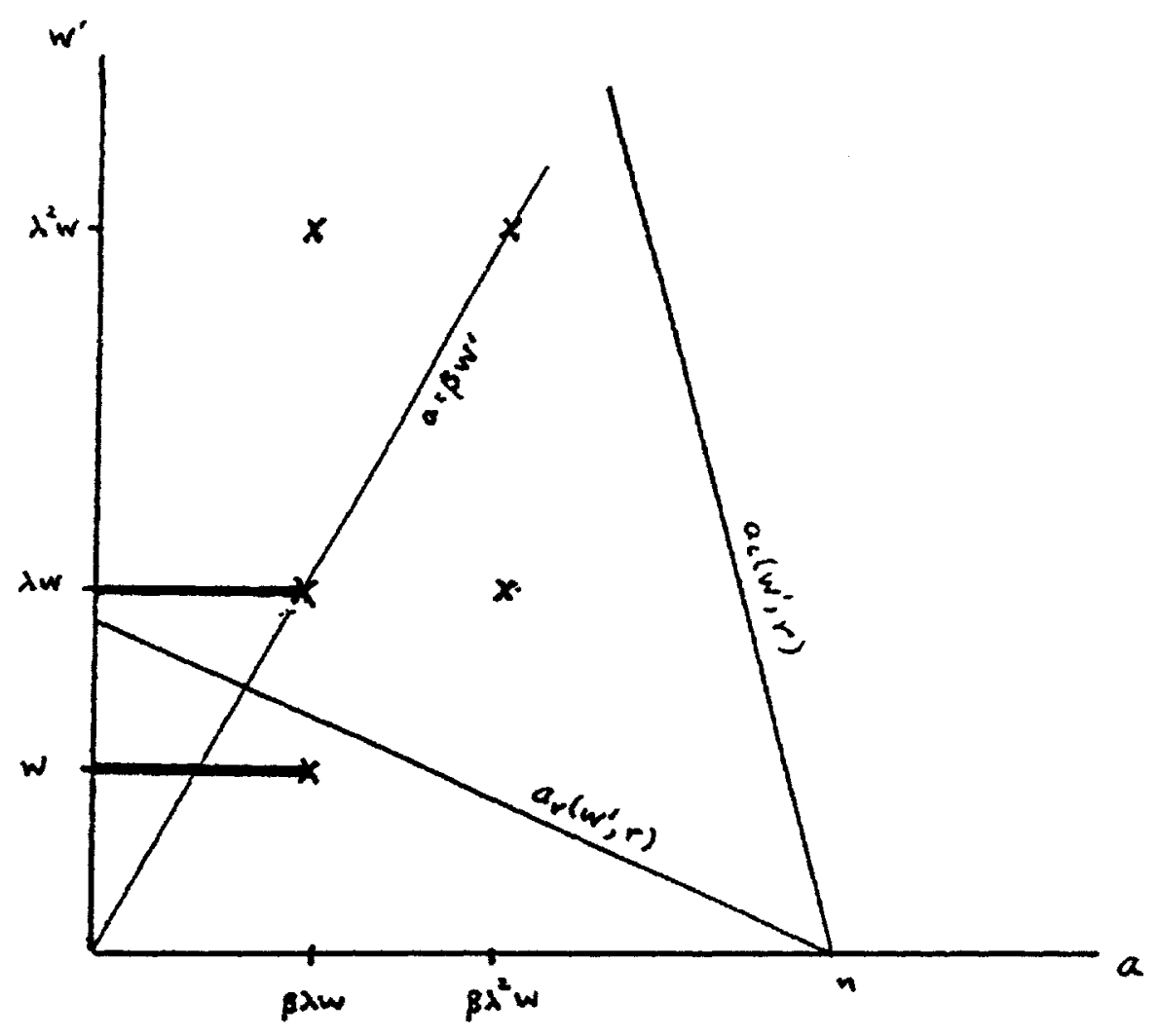

Figure 5

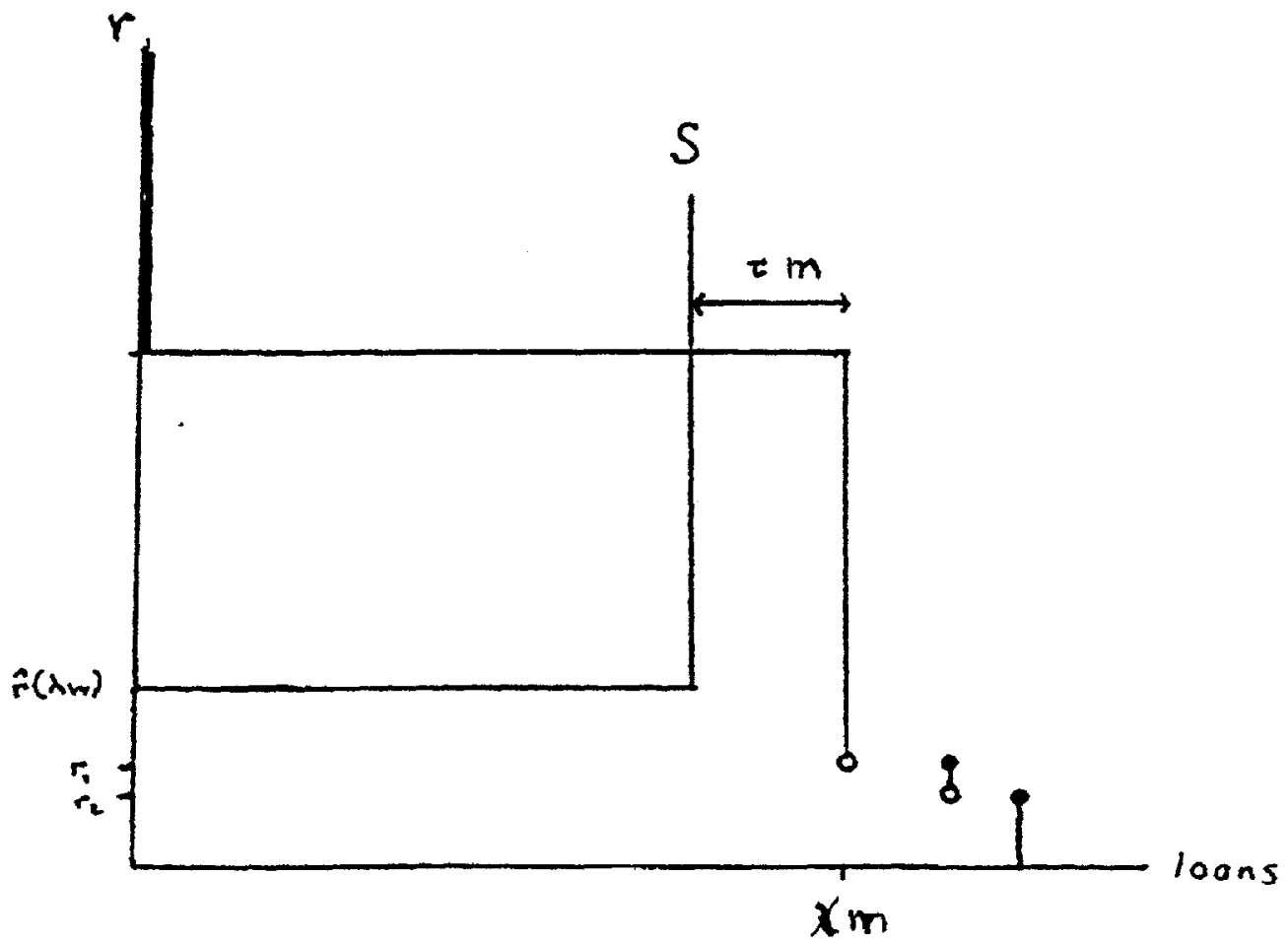

Figure 6 


\title{
1996-1997 Discussion Paper Series
}

\author{
Department of Economics \\ Columbia University \\ 1022 International Affairs Bldg. \\ 420 West 118 th Street \\ New York, N.Y., 10027
}

The following papers are published in the 1996-97 Columbia University Discussion Paper series which runs from early November to October 31 of the following year (Academic Year).

Website: $\quad$ http://www.columbia.edu/dlc/wp/econ/index.html.

You may download any papers found on this site.

For Ordering Hardcopies:

Domestic orders for discussion papers are available for purchase at the cost of $\$ 8.00$ (U.S.) Per paper and $\$ 140.00$ (US) for the series.

Foreign orders cost $\$ 10.00$ (US) per paper and $\$ 185.00$ for the series.

To order discussion papers, please write to the Discussion Paper Coordinator at the above address along with a check for the appropriate amount, made payable to Department of Economics, Columbia University. Please be sure to include the series number of the requested paper when you place an order. 
1996-97 Discussion Papers

Economics Department, Columbia University

\begin{tabular}{|c|c|c|}
\hline$\frac{1}{n c 0701}$ & W & 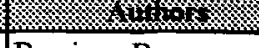 \\
\hline $9697-01$ & Fertility Behavior Under Income Uncertainty & Ranjan, P. \\
\hline $9697-02$ & Trade Restrictions, imperfect Competition and National Welfare with Foreign Capital Inflows & Ranjan, $P$. \\
\hline $9697-03$ & Restructuring an Industry during Transition: a Two-Priced Model & Ericson, $\mathrm{R}$. \\
\hline $9697-04$ & A Conformity Test for Cointegration & Dhrymes, $\mathrm{P}$. \\
\hline $9697-05$ & $\begin{array}{l}\text { Low-Wage Employment Subsidies in a Labor-Turnover Model of the 'Natural Rate' } \\
\text { (November 1996) }\end{array}$ & $\begin{array}{l}\text { Hoon, H.T. } \\
\text { Phelps, E. }\end{array}$ \\
\hline $9697-06$ & The Knowledge Revolution & Chichilnisky, G. \\
\hline $9697-07$ & The Role of Absolute Continuity in "Merging Opinions" and "Rational Learning" & $\begin{array}{l}\text { Miller. R. } \\
\text { Sanchirico, C.W. }\end{array}$ \\
\hline $9697-08$ & The Soviet Bloc and the Soviet Union: Why did they fall apart? & Desai, $\mathrm{P}$. \\
\hline $9697-09$ & Regionalism and Multilateral Tariff Cooperation & $\begin{array}{l}\text { Bagwell, K. } \\
\text { Staiger, R. }\end{array}$ \\
\hline $9697-10$ & Supplier Relations and the Market Context: A theory of handshakes & McLaren, J. \\
\hline $9697-11$ & Vertical Foreclosure with the Choice of Input Specifications & $\begin{array}{l}\text { Choi, J.P. } \\
\text { Yi, S. }\end{array}$ \\
\hline $9697-12$ & Equilibrium Vertical Foreclosure with Investment & $\begin{array}{l}\text { Choi, J.P. } \\
\text { Yi, S. }\end{array}$ \\
\hline $9697-13$ & Going Global: Transition from Plan to Market in the World Economy & Desai, $\mathrm{P}$. \\
\hline $9697-14$ & $\begin{array}{l}\text { Reciprocity, Non-discrimination and Preferential Agreements in the Multilateral Trading } \\
\text { System }\end{array}$ & $\begin{array}{l}\text { Bagwell, K. } \\
\text { Staiger, R. }\end{array}$ \\
\hline $9697-15$ & Russia's Transition Toward the World Economy: Is the Market Mechanism Working? & Desai, $P$. \\
\hline 9697-16 & A Dynamic Analysis of Licensing: The "Boomerang" Effect and Grant-Back Clauses & Choi, J.P. \\
\hline
\end{tabular}


1996-97 Discussion Papers

Economics Department, Columbia University

\begin{tabular}{|c|c|c|}
\hline ................. & . . . . . . . & 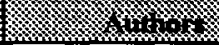 \\
\hline $9697-17$ & An Economic Theory of GATT & $\begin{array}{l}\text { Bagwell, K. } \\
\text { Staiger R.W. }\end{array}$ \\
\hline $9697-18$ & Climate Consumption and Climate Pricing from 1940 to 1990 & $\begin{array}{l}\text { Cragg, M.I. } \\
\text { Kahn, M.E. }\end{array}$ \\
\hline $9697-19$ & Coddling Fatalistic Criminals: A Dynamic Stochastic Analysis of Criminal Decision-Making & O'Flaherty, B. \\
\hline $9697-20$ & Identification and Estimation of Structural VAR and MARMA Models & Dhrymes, $\mathrm{P}$. \\
\hline $9697-21$ & Information, the Dual Economy, and Development & $\begin{array}{l}\text { Banarjee, A.V } \\
\text { Newman, A.F. }\end{array}$ \\
\hline
\end{tabular}

